\title{
Effects of lifestyle intervention in persons at risk for type 2 diabetes mellitus - results from a randomised, controlled trial
}

Vegard Nilsen ${ }^{*}$, Per S Bakke ${ }^{2}$ and Frode Gallefoss ${ }^{3}$

\begin{abstract}
Background: Lifestyle change is probably the most important single action to prevent type 2 diabetes mellitus. The purpose of this study was to assess the effects of a low-intensity individual lifestyle intervention by a physician and compare this to the same physician intervention combined with an interdisciplinary, group-based approach in a real-life setting.

Methods: The "Finnish Diabetes Risk score" (FINDRISC) was used by GPs to identify individuals at high risk. A randomised, controlled design and an 18 month follow-up was used to assess the effect of individual lifestyle counselling by a physician (individual physician group, $(\mathrm{IG})$ ) every six months, with emphasis on diet and exercise, and compare this to the same individual lifestyle counselling combined with a group-based interdisciplinary program (individual and interdisciplinary group, (IIG)) provided over 16 weeks. Primary outcomes were changes in lifestyle indicated by weight reduction $\geq 5 \%$, improvement in exercise capacity as assessed by $\mathrm{VO}_{2}$ max and diet improvements according to the Smart Diet Score (SDS).

Results: 213 participants (104 in the IG and 109 in the IIG group, 50\% women), with a mean age of 46 and mean body mass index 37, were included (inclusion rate > 91\%) of whom 182 returned at follow-up (drop-out rate 15\%). There were no significant differences in changes in lifestyle behaviours between the two groups. At baseline 57\% (IG) and 53\% (IIG) of participants had poor aerobic capacity and after intervention 35\% and 33\%, respectively, improved their aerobic capacity at least one metabolic equivalent. Unhealthy diets according to SDS were common in both groups at baseline, 61\% (IG) and 60\% (IIG), but uncommon at follow-up, 17\% and 10\%, respectively. At least 5\% weight loss was achieved by 35\% (IG) and 28\% (IIG). In the combined IG and IIG group, at least one primary outcome was achieved by $93 \%$ while all primary outcomes were achieved by $6 \%$. Most successful was the $78 \%$ reduction in the proportion of participants with unhealthy diet (almost $50 \%$ absolute reduction).
\end{abstract}

Conclusion: It is possible to achieve important lifestyle changes in persons at risk for type 2 diabetes with modest clinical efforts. Group intervention yields no additional effects. The design of the study, with high inclusion and low dropout rates, should make the results applicable to ordinary clinical settings.

Trial registration: ClinicalTrials.gov: NCT00202748

Keywords: type 2 diabetes mellitus, prevention, lifestyle, obesity

\footnotetext{
* Correspondence: vegard.nilsen@sshf.no

'Department of Internal Medicine, Sorlandet Hospital Kristiansand, Norway

Full list of author information is available at the end of the article
} 


\section{Background}

The incidence of type 2 diabetes mellitus is increasing worldwide. Both genetic predisposition and behavioural and environmental risk factors are needed to develop type 2 diabetes [1]. Recent epidemiologic research suggests that the increased incidence of type 2 diabetes is largely due to changes in lifestyle factors such as diet and physical activity [2]. Lifestyle modification in high risk individuals has been proven effective in reducing type 2 diabetes [3];[4], more effective than drug treatment [4] and with sustained reduction in diabetes incidence $[5,6]$. Cochrane reviews summarizes that exercise combined with diet can decrease the incidence of type 2 diabetes in high risk individuals, but that additional research is needed to reveal the best type of diet $[7,8]$. According to the International Diabetes Federation, up to $80 \%$ of type 2 diabetes is preventable by adopting a healthy diet and increasing physical activity. Even small weight losses combined with about 30 minutes of activity per day, are in many instances enough to prevent or at least postpone the disease [3,4]. One $\mathrm{kg}$ of weight lost is associated with a $16 \%$ reduction in diabetes risk [9].

Meta-analysis indicate that dietary counselling interventions for persons with obesity or overweight produce modest weight losses that diminish over time [10]. Compared with diet alone, diet in combination with exercise gives a $20 \%$ greater initial and sustained weight loss after one year [11]. Successful weight loss studies are usually conducted in tightly randomised, controlled trials (RCTs) with low inclusion rates and low external validity and applicability to clinical practice (Efficacy studies; "Can it work?") [12]. Effectiveness studies ("Does it work?) are usually studies with looser study designs (often simple audits or before-after designs), high inclusion rates, and brief feasible interventions, with focus on the ability to maintain the intervention as standard practice [12]. Patients included in such studies are more often in alignment with patients met in common clinical settings. There is an unmet need to develop practical, sustainable and low-intensity interventions for the large number of people at risk for type 2 diabetes [13]. In this trial, individual lifestyle counselling by a physician, with emphasis on diet and exercise, was provided for individuals at risk of type 2 diabetes. The effects of this intervention, alone or combined with an additional group-based interdisciplinary program over 16 weeks, was assessed in a randomised, controlled design with an 18 month follow-up.

\section{Methods}

\section{Subjects and study design}

The "Finnish Diabetes Risk score" (FINDRISC) was used to identify individuals at high risk for type 2 diabetes, assessing waist circumference, body mass index (BMI), age, medication against high blood pressure, activity, history of high blood glucose and daily consumption of vegetables/fruits. FINDRISC is found to be a simple and feasible tool, i.e. fast, non-invasive, reliable and at the start of this trial, the best available tool for use in clinical practice $(14 ; 15)$. It is also a good predictor of coronary artery disease (CAD), stroke and total mortality [16]. The total score ranges between $0-20$. A FINDRISC-score $\geq 9$ is found to identify $>70 \%$ of new cases of drug treated type 2 diabetes within five years [14]. Hence, all general practitioners (GPs) in the four nearest municipalities to the hospital were each supplied with ten FINDRISC-questionnaires by post, asked to use them on patients at risk for type 2 diabetes. They were requested to refer individuals aged 18-64 with a FINDRISC-score $\geq 9$ to the hospital. The Regional Committee for Medical Research Ethics of southern Norway approved the study.

All referred individuals were assessed by the same physician in a clinical examination. A thorough conversation about family history of diabetes and heart disease was carried out, as well as tobacco and alcohol consumption assessments. Finally, the following information, statements and advices were given:

1. the probability of type 2 diabetes can be reduced by $50 \%$ with only small changes in lifestyle and weight

2. the same changes can reduce the probability for heart disease considerably

3. The following were emphasized:

- to increase the consumption of fruit and vegetables

- to get at least 30 minutes of activity pr. day

- to achieve at least 5\% loss of weight

- to reduce the consumption of sugar and saturated fat

- to use oil as the main source of fat

- to consume cod-liver oil daily

At the end of the consultation, participants were asked if they wanted to participate in the study. Exclusion criteria were: a diagnosis of diabetes mellitus, the presence of serious heart, lung, kidney or liver failure, serious psychiatric illness, substance abuse and not mastering the Norwegian language. A written informed consent was signed. They were randomly assigned to an "individual physician group" (IG) or an "individual plus interdisciplinary group" (IIG) by use of closed envelope method with unknown block sizes. All GPs received written information about inclusion, group allocation and aims and advices given. Flow of participants through the trial is shown in Figure 1. 


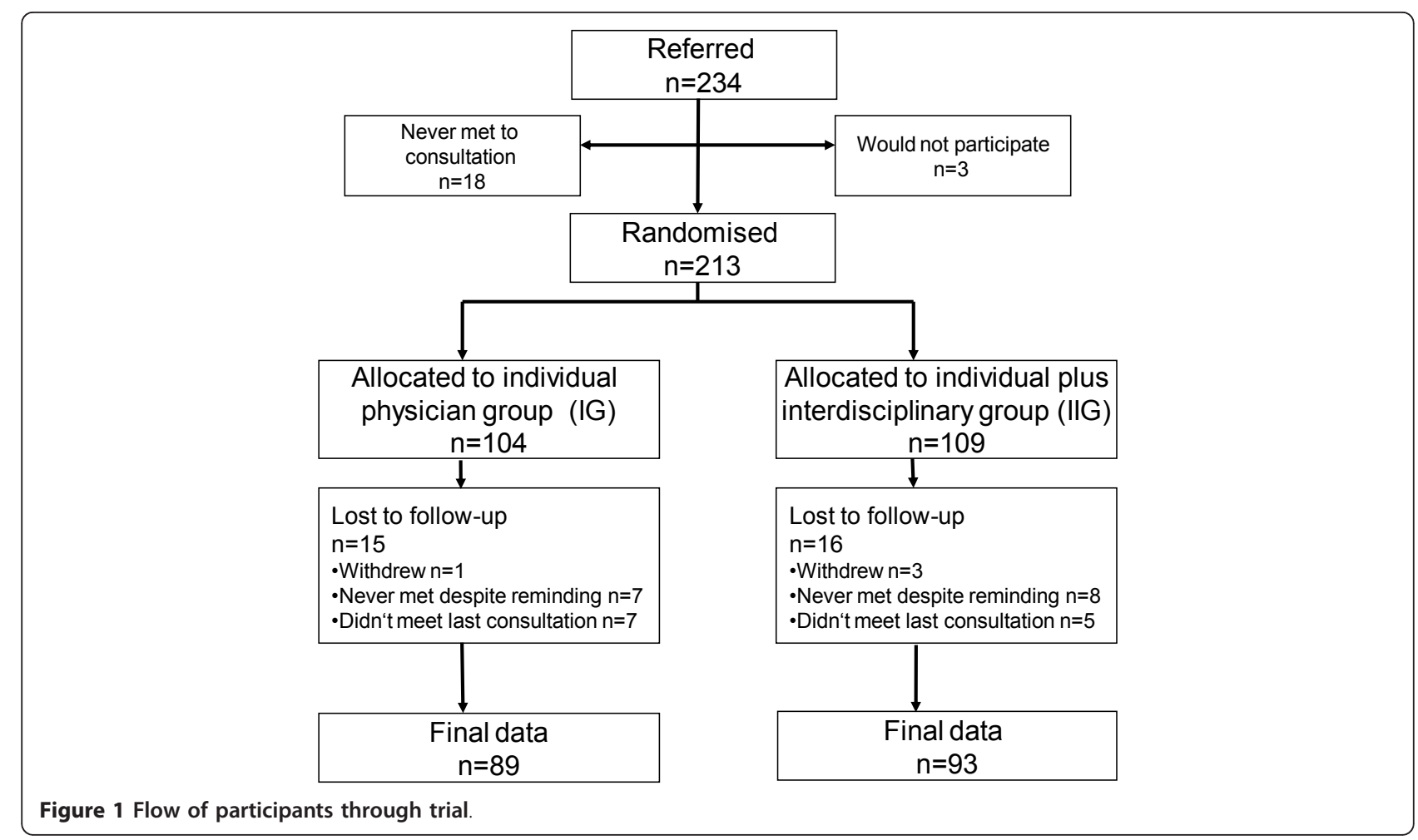

Participants in the IG group consulted the study physician at six, twelve and eighteen months after randomisation and otherwise received care from their GP as usual. The study physician used elements of motivational interviewing during these consultations.

In addition, the IIG group participated in a groupbased program ( $\leq$ ten participants), one day (five hours per day) each week for six weeks and a new gathering after twelve weeks. A systematic review of their situation was given, with emphasis on how to avoid diabetes and CAD, by increasing the level of knowledge and self-consciousness (Figure 2). The topics for these group sessions were research findings and factual information about nutrition and physical activity, habit change, action plans, risk situations, coping strategies, etc. The group intervention also included a variety of physical training. The IIG program was interdisciplinary (dietician, physiotherapist, ergonomist, nurse and physician). Motivational interviewing techniques were utilised. This is a wellknown, scientifically-tested method-, which outperforms traditional advice given in the treatment of a broad range of behavioural problems and diseases [17]. An individual 30-minutes consultation with a nurse or ergonomist completed the intervention one month after the last group meeting.

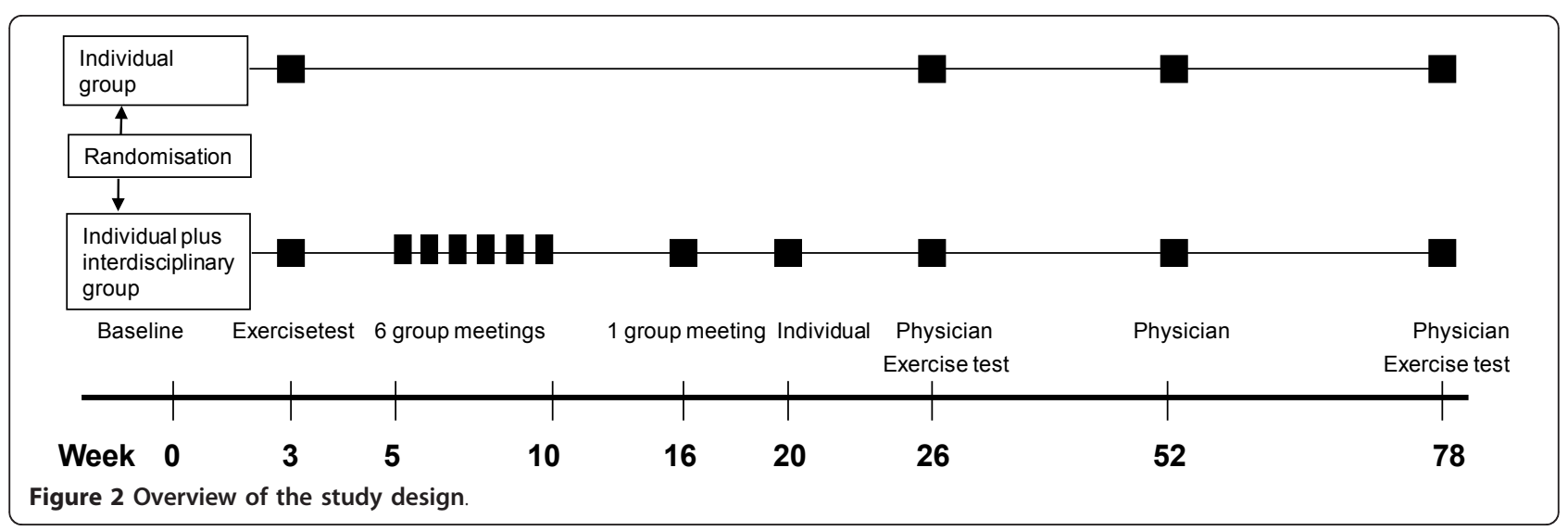




\section{Assessments}

At every visit to the study physician, the following assessments were performed: fasting blood sample, systolic and diastolic blood pressure (SBP and DBP) according to recommended standards [18], waist circumference at a level midway between the lowest rib and the iliac crest to the nearest $\mathrm{cm}$, height without shoes to the nearest $\mathrm{cm}$ (only first visit) and weight in indoor clothes to the nearest $100 \mathrm{~g}$. Blood pressures were measured by an Omron M41 and weight with a Seca 771. An oral glucose tolerance test (OGTT), required to rule out diabetes and to identify patients with impaired glucose tolerance (IGT), was not performed prior to nor during the study. These pragmatic inclusion criteria fits well with the aim of the study to test the effects of step one life style intervention in a group at risk for diabetes. The Smart Diet Score questionnaire was used; a fast, simple and validated tool for food assessment resulting in a diet score which ranges between 15 and 45 points [19]. A diet score between 15-29 points is categorised as "unhealthy", 30-37 points as "somewhat unhealthy" and $\geq 38$ points as a "healthy" diet. A question was added to the questionnaire to ascertain the number of days with cod-liver oil consumption during the last week.

A physical test on a treadmill was carried out during the first month after randomisation and repeated after six and eighteen months, to determine maximal aerobic capacity (VO2max), utilising a modified Bruce protocol designed for people in poor physical condition [20]. The results were categorised into six levels according to normative data for $\mathrm{VO} 2 \mathrm{max}$ for gender and age: very poor, poor, fair, good, excellent and superior aerobic capacity [21]. An increase in exercise capacity of 3,5 ml/ $\mathrm{kg}$ per minute (one metabolic equivalent (MET)) is shown to be associated with a 12 percent improvement in survival [22].

\section{Definition of end points}

Primary outcomes were changes in lifestyle according to established goals that have been shown to reduce incidence of type 2 diabetes, improve health and to improve cardiovascular risk profile. These were defined as:

- weight reduction $\geq 5 \%$ [23]

- reduction in waist circumference of $\geq 5 \mathrm{~cm}$ [24]

- improvement in exercise capacity of one MET [22]

- consumption of cod-liver oil $\geq$ five days per week [25]

- $\geq 4$ point increase in Smart Diet Score. The outcome for this diet change is an arbitrary threshold which is not evidence based. It reflects an improvement in four out of 15 areas of diet

\section{Statistical analyses}

Sample size was based upon a decision that a difference between groups in all main outcomes of $>20 \%$ was clinically important. Therefore, number needed to treat $(\mathrm{NNT})=$ five, to experience one extra person with a favourable main outcome with the additional group session approach. The spontaneous rate of achieving the primary outcomes was estimated to be approximately $20 \%$. The dropout rate was estimated to $15-20 \%$. On the basis of these assumptions, with a power $>80 \%$ ( $\beta \leq$ 0.20 ), a significance level $\alpha \leq 0.05$, and a two-sided test, the appropriate study size was calculated to be 200 participants, with 100 in each group. Statistical package for Social Sciences 16 (SPSS Inc. Chicago, USA) was employed for statistical analyses. The $\chi^{2}$ test was used to assess the differences between groups when variables were categorical and McNemar test when testing within-group changes from baseline to follow-up. The independent sample t-test was used to assess differences in means between study groups for continuous variables with normal distribution. Paired t-test was used for (within-group) comparisons of quantitative data between baseline and follow-up at 18 months.

\section{Results}

65 GPs out of about 90 referred 234 individuals from March 2004 to September 2005. 216 turned up for consultation (Figure 1). 213 participants were randomised (inclusion rate $>91 \%$ ) of whom 182 completed the study $(>85 \%)$. Mean (standard deviation $=$ SD) FINDRISC score was $12,0(2,7)$ for the IG-group and 12,3 $(2,8)$ for the IIG-group. 173 answered the diet questionnaire at the end of study (95\% of completers). 201 performed the treadmill test at baseline (94\% of included), 168 after six months and 131 (72\% of completers) at the end of the study. The dropout rate from baseline to end of study was comparable in the IG- and the IIG group (15\%), and comparable between genders. The drop-outs, as compared with completers, were 3,8 years younger $(43,2$ versus 47,0$)$, more often on antidepressants $(23 \%$ versus $6 \%)$, had higher BMI $(38,9$ versus 36,4$)$, lower aerobic capacity $(24,1$ versus 27,2$)$, lower diet score $(27,5$ versus 29,0$)$ and doubled frequency of both daily smoking (50\% versus $21 \%$ ) and long term sick leave or disability (57\% versus $28 \%$ ), (all p values < 0.05 ). Participants in the IIG group attended on average five $(5,2)$ of the seven group meetings, and 94\% attended the final, individual consultation and assessment.

Randomisation seemed successful for all baseline variables except for BMI. Participants in the IG group had significantly lower BMI than persons in the IIG group (Table 1). $90 \%$ of participants were obese (BMI > 30). Weight reducing drugs (orlistat or sibutramin) were used by $10 \%$ in the IG-group and 5\% in the IIG-group at baseline ( $\mathrm{p}=$ 
$0,15)$, at follow-up they were used by $4 \%$ in the IG-group and by $5 \%$ in the IIG-group $(p=0,79)$. None were using metformin or glitazones. Anti-hypertensive drugs were used among $36 \%$ of all at baseline and $37 \%$ at follow-up. The percentage of subjects with hypertension (defined by systolic blood pressure $\geq 140 \mathrm{mmHg}$ and/or diastolic pressure $\geq 90 \mathrm{mmHg}$ [26] or use of anti-hypertensive drugs) was $71 \%$ in the IG-group and $76 \%$ in the IIG-group ( $\mathrm{p}=$ $0,25)$ at baseline, and $79 \%$ and $82 \%(p=0,40)$, respectively, at follow-up. Hypertension were seen more often among subjects using anti-hypertensive drugs compared to subject not using it at baseline, i.e. $75 \%$ versus $59 \%$, respectively ( $p=0,02$ ), but at follow-up this difference was not significant, $76 \%$ versus $65 \%$ respectively $(p=0,13)$.

Poor or very poor aerobic capacity was found in $55 \%$ of all participants, and was twice as frequent among men (75\%) as among women (36\%), ( $\mathrm{p}<$ $0,001)$. Aerobic capacity at baseline was weakly, inversely correlated with BMI $\left(\mathrm{r}^{2}=0,22, \mathrm{p}<0,001\right)$. An unhealthy diet was found in $60 \%$ of all participants, and more frequently among daily smokers (76\%) compared with the occasional- and non-smokers (55\%), (p $=0,008)$. More than two-thirds had lower education (primary or secondary education only). For individuals with primary and/or secondary education only, mean diet score was 2,2 points lower $(p<0,001)$, mean aerobic capacity $4,6 \mathrm{ml} / \mathrm{kg} / \mathrm{min}$. lower $(\mathrm{p}<0,001)$ and the frequency of daily smoking more than doubled ( $30 \%$ versus $12 \%, p=0,006$ ), compared to those with higher education.

From baseline to follow-up there were no significant, additional effects of group intervention (Tables 1 and 2). Thus, the forthcoming results are presented as beforeafter differences for all participants combined. At least one primary outcome (Table 2) was achieved by $93 \%$ while all primary outcomes were achieved by $6 \%$, indicating an important change in lifestyle. Most successful was the $78 \%$ reduction in the proportion of participants with unhealthy diet (almost 50\% absolute reduction, Figure 3). The number of individuals consuming cod-liver oil $\geq 5$ days per week increased by $25 \%$ and was thereby doubled. There was a mean increase in maximal aerobic capacity of $9 \%$ which was evident after six months and thereafter stable. One third of participants improved their aerobic capacity to an extent which is known to improve health (1 MET). Mean weight loss from baseline was modest: $1,9 \mathrm{~kg}$ (SD 5,6), 2,0 kg (SD 6,2) and 2,8 $\mathrm{kg}(\mathrm{SD} 7,1)$ respectively, at 6, 12 and 18 months assessments, with no gender differences. One-third had a weight reduction $\geq 5 \%$ (mean $9,4 \%$ (SD 4,0)), one third had a weight reduction less than $5 \%$ (mean 2,1\% (SD $1,4)$ ) and the last third gained weight (mean $4,0 \%$ (SD $3,8)$ ). From baseline to follow-up there were no change in the proportion of participants with plasma glucose $\geq$
$7,0 \mathrm{mmol} / \mathrm{l}(6 \%)$, IFG (15\%) or normoglycemia (79\%), and no between group differences.

\section{Discussion}

This study confirms that changes in lifestyle are possible in individuals at risk for type 2 diabetes, with modest clinical effort. This applies to both genders regardless of educational status. Almost half of participants abandoned their unhealthy diet, one third obtained a healthimproving weight loss and one third improved their fitness by one MET. Adding interdisciplinary group-based counselling to the individual physician-based intervention, gave no additional effects.

Limitations of the study must be considered. First, dietary intake was assessed by self-report and may present a source of recall bias. General underreporting compounded with food-specific underreporting is frequent and may increase with increasing BMI $[27,28]$. Second, $28 \%$ of completers failed to perform the treadmill test, which weakens the results for change in fitness. We can consider the worst case scenario i.e. that all who did not attend the last test and all who dropped out did not improve their aerobic capacity. The success rate would then fall from 33 to $20 \%$ if success is defined as improvement of VO2max of 1 MET. However, we contend that compliance with treadmill testing for almost three fourths of completers in such an unselected study population is a high standard result. Third, the study-physician (first author) was not blinded to the randomisation status of the participants. This may have biased the results. Fourth, dropouts differed from participants who completed testing by being younger and having poorer lifestyle parameters. Hence, withdrawal in this study does not occur at random, but is more common among individuals who are dissatisfied with their life style [10]. It is a paradox, and a major healthcare challenge, that those who have greatest need for a change in lifestyle are also those who are most likely to discontinue an intervention. Fifth, the generalisability of the findings in this study could be limited by self-selection bias or healthy volunteer bias. Thus, extrapolating these results to the general population may overestimate the effects. However, the results should be valid for patients at risk for diabetes according to the FINDRISC questionnaire.

A major strength of this study is the low drop-out rate compared with other weight loss studies. A meta analysis of 121 pharmaceutical randomised controlled trials with weight loss or weight gain prevention as major end points, found a drop-out rate of $37 \%$ at one year [29]. Studies including behaviour modification among overweight and obese out-patients report drop-out rates after one and two years of $53-77 \%[30,31]$. The aim of this study was to evaluate a practical and low-intensity 
Table 1 Baseline characteristics of 213 included subjects and changes in selected clinical and metabolic variables from baseline to follow-up at 18 months among 182 completers of the study.

\begin{tabular}{|c|c|c|c|c|c|c|c|c|c|c|}
\hline & \multicolumn{3}{|c|}{$\begin{array}{l}\text { Individual physician group } \\
\qquad(\text { IG) } \\
\qquad=104\end{array}$} & \multicolumn{3}{|c|}{$\begin{array}{c}\text { Individual plus interdisciplinary } \\
\text { group (IIG) } \\
\mathrm{n}=109\end{array}$} & \multicolumn{4}{|c|}{$\begin{array}{c}\text { All } \\
n=213\end{array}$} \\
\hline & \multicolumn{3}{|c|}{ Baseline } & \multicolumn{3}{|c|}{ Baseline } & \multicolumn{4}{|c|}{ Baseline } \\
\hline Age & \multicolumn{3}{|c|}{$45,9(11)$} & \multicolumn{3}{|c|}{$47,0(11)$} & \multicolumn{4}{|c|}{$46,5(11)$} \\
\hline Gender, men, \% & \multicolumn{3}{|c|}{53} & \multicolumn{3}{|c|}{47} & \multicolumn{4}{|c|}{50} \\
\hline Married or cohabiting, $\%$ & \multicolumn{3}{|c|}{79} & \multicolumn{3}{|c|}{69} & \multicolumn{4}{|c|}{74} \\
\hline High school or university, \% & \multicolumn{3}{|c|}{27} & \multicolumn{3}{|c|}{29} & \multicolumn{4}{|c|}{28} \\
\hline Employed, \% & \multicolumn{3}{|c|}{64} & \multicolumn{3}{|c|}{61} & \multicolumn{4}{|c|}{62} \\
\hline \multirow[t]{3}{*}{ BMI } & \multicolumn{3}{|c|}{$35,9(6)$} & \multicolumn{3}{|c|}{$37,6(6)$} & \multicolumn{4}{|c|}{$36,8(6)$} \\
\hline & Baseline & Follow-up & $P$ value & Baseline & Follow-up & $P$ value & Baseline & Follow-up & $\Delta$-value & $P$ value \\
\hline & \multicolumn{3}{|c|}{$\mathrm{n}=89$} & \multicolumn{3}{|c|}{$\mathrm{n}=93$} & \multicolumn{4}{|c|}{$n=182$} \\
\hline Weight, kg & $111,7(22)$ & $108,7(23)$ & $<0,001^{*}$ & $110,5(22)$ & $108,0(20)$ & $0,001^{*}$ & $111,1(22)$ & $108,3(21)$ & 2,8 & $<0,001^{*}$ \\
\hline $\mathrm{BMI}, \mathrm{kg} / \mathrm{m}^{2}$ & $35,8(6)$ & $34,8(6)$ & $<0,001^{*}$ & $37,0(6)$ & $36,2(6)$ & $<0,001^{*}$ & $36,4(6)$ & $35,5(6)$ & 0,9 & $<0,001^{*}$ \\
\hline Waist circumference, cm & $119(14)$ & $115(15)$ & $<0,001^{*}$ & $118(15)$ & $116(14)$ & $<0,001^{*}$ & $118(14)$ & $115(14)$ & 3 & $<0,001^{*}$ \\
\hline Aerobic capacity, $\mathrm{ml} / \mathrm{kg} / \mathrm{min}^{2} 2$ & $27,4(8)$ & $29,8(8)$ & $<0,001^{*}$ & $26,4(8)$ & $28,7(7)$ & $<0,001^{*}$ & $26,9(8)$ & $29,2(7)$ & 2,3 & $<0,001^{*}$ \\
\hline Heart rate at end of exercise test ${ }^{2}$ & $159(22)$ & $163(21)$ & $0,009^{*}$ & $159(19)$ & $161(21)$ & $0,17^{*}$ & $159(20)$ & $162(21)$ & 3 & $0,004^{*}$ \\
\hline SBP, $\mathrm{mmHg}$ & $144(18)$ & $147(19)$ & $0,09^{*}$ & $144(20$ & $143(19)$ & $0,84^{*}$ & $144(19)$ & $145(19)$ & 1 & $0,37^{*}$ \\
\hline $\mathrm{DBP}, \mathrm{mmHg}$ & $90(11)$ & $91(10)$ & $0,42^{*}$ & $88(10)$ & $91(11)$ & $0,03^{*}$ & $89(11)$ & $91(11)$ & 2 & $0,04^{*}$ \\
\hline Fasting plasma glucose, $\mathrm{mmol} / \mathrm{l}$ & $5,5(0,8)$ & $5,6(0,7)$ & $0,69^{*}$ & $5,6(0,8)$ & $5,8(1,2)$ & $0,06^{*}$ & $5,6(0,8)$ & $5,7(1,0)$ & 0,1 & $0,08^{*}$ \\
\hline $\mathrm{HbA1c}, \%$ & $5,6(0,4)$ & $5,6(0,5)$ & $0,11^{*}$ & $5,6(0,4)$ & $5,6(0,5)$ & $0,91^{*}$ & $5,6(0,4)$ & $5,6(0,5)$ & 0 & $0,29 *$ \\
\hline Total cholesterol, mmol/l & $5,5(1,1)$ & $5,3(1,0)$ & $0,09^{*}$ & $5,4(1,1)$ & $5,2(1,1)$ & $0,07^{*}$ & $5,4(1,1)$ & $5,3(1,0)$ & 0,1 & $0,01^{*}$ \\
\hline HDL cholesterol, mmol/l & $1,18(0,3)$ & $1,23(0,3)$ & $0,006^{*}$ & $1,28(0,4)$ & $1,25(0,4)$ & $0.17^{*}$ & $1,23(0,4)$ & $1,24(0,3)$ & 0,01 & $0,40^{*}$ \\
\hline Triglycerides, mmol/l & $1,9(1,0)$ & $1,6(0,7)$ & $<0,001^{*}$ & $1,8(1,4)$ & $1,5(0,8)$ & $0,01^{*}$ & $1,9(1,2)$ & $1,5(0,7)$ & 0,4 & $<0,001^{*}$ \\
\hline Diet score, mean & $29(4)$ & $33(4)$ & $<0,001^{*}$ & $29(4)$ & $34(3)$ & $<0,001^{*}$ & $29(4)$ & $34(4)$ & 5 & $<0,001^{*}$ \\
\hline Healthy diet, $\%$ of all & 2 & 16 & $0,007 \#$ & 1 & 20 & $<0,001 \#$ & 2 & 18 & 16 & $<0,001 \#$ \\
\hline Unhealthy diet, $\%$ of all & 60 & 17 & $<0,001 \#$ & 56 & 10 & $<0,001 \#$ & 58 & 13 & 45 & $<0,001 \#$ \\
\hline Daily smoking, \% & 21 & 17 & $0,22 \#$ & 18 & 18 & 1,0\# & 20 & 17 & 3 & $0,34 \#$ \\
\hline Days/week using cod liver oil & $1,8(3)$ & $3,4(3)$ & $<0,001^{*}$ & $1,8(3)$ & $4,1(3)$ & $<0,001^{*}$ & $1,8(3)$ & $3,7(3)$ & 1,9 & $<0,001^{*}$ \\
\hline Cod liver oil $\geq 5$ days per week & 25 & 43 & $0,02 \#$ & 26 & 54 & $<0,001 \#$ & 25 & 49 & 24 & $<0,001 \#$ \\
\hline
\end{tabular}

Values are means with standard deviations in parenthesis, unless stated otherwise.

${ }^{1}$ Inter-group differences with $\mathrm{p}<0.05$ based on Chi-Square test for categorical variables and independent sample t-test for quantitative data

*paired sample t test \# McNemar test

${ }^{2} N=63 \& n=66$ in the IG and IIG group, respectively

$\Delta$-value displays the actual difference between baseline and follow-up

Table 2 Success in achieving primary outcomes by 18 months according to treatment group by proportions (\%).

\begin{tabular}{|c|c|c|c|c|}
\hline Primary outcome & $\begin{array}{c}\text { Individual physician } \\
\text { group (IG) } \\
n=89\end{array}$ & $\begin{array}{l}\text { Individual and interdiciplinary group (IIG) } \\
\qquad \mathrm{n}=93\end{array}$ & P value* & $\begin{array}{c}\text { All } \\
\mathrm{n}=182\end{array}$ \\
\hline 1. Weight reduction $\geq 5 \%$ & 36 & 28 & 0,25 & 32 \\
\hline 2. Waist circumference reduction $\geq 5 \mathrm{~cm}$ & 42 & 30 & 0,11 & 36 \\
\hline 3. Improved diet score $\geq 4$ points & 55 & 63 & 0,28 & 59 \\
\hline 4. Cod-liver oil at least 5 days a week & 43 & 54 & 0,15 & 49 \\
\hline Exercise test from baseline to follow-up & $n=63$ & $\mathrm{n}=64$ & & \\
\hline 1. Improved exercise test $\geq 1 \mathrm{MET}$ & 35 & 33 & 0,80 & 34 \\
\hline
\end{tabular}



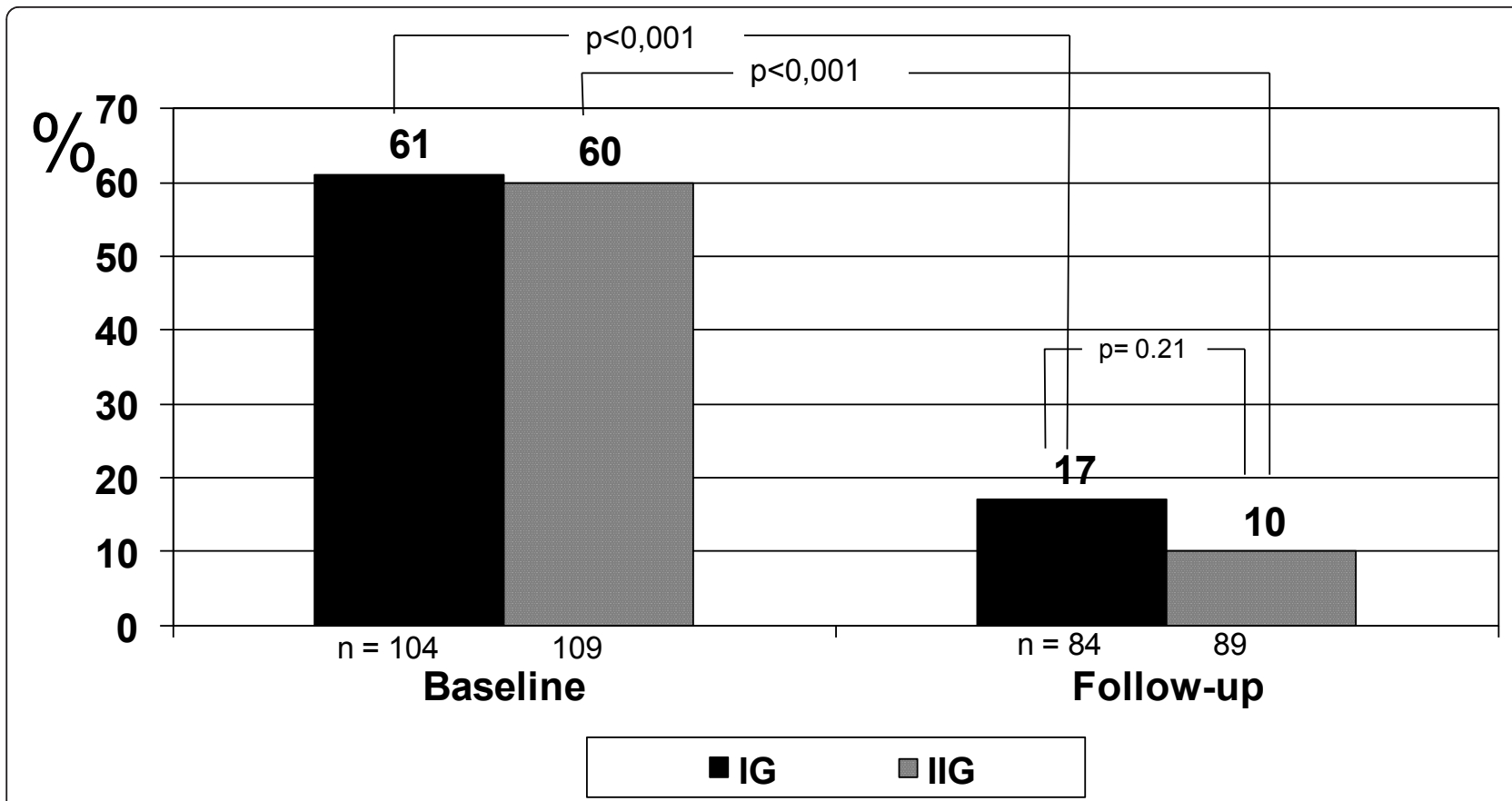

Figure 3 Reduction in proportion of patients with unhealthy diet from baseline to follow-up

intervention with high external validity. An inclusion rate of $>91 \%$ of those referred and a participation rate of $>98 \%$ among those who turned up for consultation, no excluded individuals and a drop-out rate $<15 \%$, is in accordance with this aim and increases the general applicability of the study results to common clinical settings. Low education was associated with a poorer diet, lower aerobic capacity and smoking, as found in other studies and reviews [32,33]. These factors and their interactions are possible confounders. These associations were not tested in an interaction term, since such results cannot be utilized in any clinically meaningful way. However, education level did not affect the success with respect to primary outcome achievements.

An unexpected finding was the much higher prevalence of poor or very poor aerobic capacity for gender and age at baseline among males compared with females. Some of the difference can be explained by a lower heart rate among males at the end of the first exercise test. This finding may reflect lower motivation and maximal effort, but may also be influenced by a trend toward more common use of beta blockers among men than women $(25 \%$ versus $15 \%, \mathrm{p}=0,08)$. However, at the final test, both use of beta blockers and maximal heart rate was comparative between genders (20\% versus $19 \%, \mathrm{p}=0,84)$. Further, the lower aerobic capacity observed in males was not explained by higher BMI. Indeed, BMI in males tended to be lower than in the female group $(36,1$ versus $37,4, p=0,10)$. Therefore given that neither beta blocker use nor BMI differences explain the lower aerobic capacity observed in this group of obese males, we do not have a clear explanation for the difference observed between genders. We note that FINDRISC has a better ability to detect men than women with low aerobic capacity. As far as we know, no one before has previously described the aerobic capacity in individuals screened by FINDRISC.

The short duration and low intensity intervention may explain the absence of additive effect for the groupbased, interdisciplinary approach. Svetkey et al found a $8,5 \mathrm{~kg}$ initial weight loss in 1032 overweight or obese adults with hypertension/dyslipidemia after six months with 20 group-based meetings, but gradually this weight loss was reduced over the next 30 months to $3,5 \mathrm{~kg}$ [34]. Although statistically significant, there was little difference in final weight loss with regard to whether they after the first six months were randomised to monthly personal contact, free use of internet technology or selfdirected control. Modest weight loss is nonetheless clinically important since there is a preferential loss of the more pathogenic visceral adipose tissue (VAT) compared with subcutaneous abdominal adipose tissue (SAT) with modest weight loss [35]. A Cochrane review of long-term non-pharmacological weight loss interventions for adults with pre-diabetes, found weight loss of $2,8 \mathrm{~kg}$ and $2,6 \mathrm{~kg}$, respectively, after one and two years, which is comparable with the weight loss in this study [36]. Further, the weight loss in this study is even more clinically important if this result is compared with the natural concomitant weight gain found in population-based surveys $[37,38]$. 
The effects on glucose metabolism and lipids were modest. Despite the favourable lifestyle changes achieved, no difference was observed in the fasting plasma glucose and HbA1c values, or the proportion of subjects with impaired fasting glucose, within the 18month study duration. Subgroup analyses including participants with both $\geq 5 \%$ weight reduction and improved aerobic capacity $\geq 1$ MET $(\mathrm{n}=24)$ showed statistically significant $(\mathrm{p}<0.05)$ changes from baseline to followup; a HbA1c reduction from 5,8 to $5,5 \%$, drop in triglyceride levels from 2,0 to $1,3 \mathrm{mmol} / \mathrm{l}$ and in total cholesterol from 5,5 to $5,0 \mathrm{mmol} / \mathrm{l}$. Blood pressure was not improved, in fact there was an increase in diastolic blood pressure in the IIG group. The prevalence of hypertension was very high, and higher among users of antihypertensive medications. Subgroup analyses including the same 24 participants from above with both $\geq 5 \%$ weight reduction and improved aerobic capacity $\geq 1$ MET, showed systolic/diastolic blood pressure reduction of $7 / 4 \mathrm{mmHg}$ which significantly differed compared to a rise of $3 / 3 \mathrm{mmHg}$ in the rest of the participants. Favourable metabolic improvements were achieved among subjects who significantly changed their lifestyle, not among the others. Use of anti-hypertensive or lipid lowering drugs did not change during the study.

Is there a lack of knowledge with regard to what persons at risk of type 2 diabetes should do to avoid type- 2 diabetes? The "Study to Help Improve Early evaluation and management of risk factors Leading to Diabetes" (SHIELD) demonstrates appropriate knowledge and healthy attitudes in individuals with or at risk for type 2 diabetes [39]. Despite this, only $28 \%$ of individuals at high risk for diabetes were exercising regularly and only $14 \%$ were following a prescribed diet. Patient empowerment has been advocated as an approach to improve this gap between patient knowledge and behaviour [39], which is comparable to the principles of Motivational Interviewing (MI) used in our study. Although different "dosages" of MI were performed in the IG and IIG groups, both groups were approached with MI, which may partly explain the lack of differences between intervention groups.

Previously published clinical trials show impressive results with relative risk reductions for type 2 diabetes of $58 \%$ for individuals with impaired glucose tolerance (IGT) $[3,4]$. Despite this, the World Health Organization estimates that the number of diabetes deaths will double between 2005 and 2030. In many European countries and in the US, adult obesity has reached epidemic proportions with a prevalence of approximately $34 \%$ $[38,40]$, coupled with a $34 \%$ prevalence of overweight [38]. Strategies to prevent weight gain on a population level are poorly understood [41] and there remains a lack of evidence for an effective intervention to prevent obesity [42]. To stop the epidemic, collaboration between academic, governmental, industrial and health care sectors is needed [43]. This implies that elements such as food supply, the availability of sweets, transport policy, advertising, labelling and prices have to be evaluated. Until governmental implementation of effective strategies to reduce the invasion of the metabolic syndrome is assured, an individual approach as shown in this study can be utilised with modest clinical efforts and clinically important results.

\section{Conclusion}

FINDRISC identifies subjects with high frequency of unhealthy lifestyle parameters. It is possible to accomplish important lifestyle changes in these subjects with modest efforts to prevent or delay development of type 2 diabetes or cardiovascular disease. Group intervention yields no additional effects. The results should be applicable to ordinary clinical settings.

\section{Acknowledgements}

We thank Mirjam Smedsrød, Signegun Romedal, Karin Hesseberg and Charlotte Holkov for delivering the intervention, Forskningsenheten Sørlandet sykehus for all support and Sørlandet kompetansefond for funding.

Sources of support included The Competence Development of Southern Norway and Department of Science, Sorlandet Hospital HF.

\section{Author details}

${ }^{1}$ Department of Internal Medicine, Sorlandet Hospital Kristiansand, Norway. ${ }^{2}$ Institute of Internal Medicine, University of Bergen, Norway. ${ }^{3}$ Department of Pulmonary Medicine, Sorlandet Hospital Kristiansand, Norway.

\section{Authors' contributions}

In this study all authors participated in the design and coordination of the study. VN conducted literature review, did all the clinical work and is the main author. FG helped to draft the manuscript and provided advice on data analysis. All authors read and approved the final manuscript.

\section{Competing interests}

The authors declare that they have no competing interests.

Received: 29 March 2011 Accepted: 25 November 2011 Published: 25 November 2011

\section{References}

1. Alonso-Magdalena P, Quesada I, Nadal A: Endocrine disruptors in the etiology of type 2 diabetes mellitus. Nat Rev Endocrinol 2011, 7(6):346-53.

2. van Dam RM: The epidemiology of lifestyle and risk for type 2 diabetes. Eur J Epidemiol 2003, 18(12):1115-25.

3. Tuomilehto J, Lindstrom J, Eriksson JG, Valle $\Pi$, Hamalainen $H$, llanneParikka $P$, et al: Prevention of type 2 diabetes mellitus by changes in lifestyle among subjects with impaired glucose tolerance. $N$ Engl J Med 2001, 344(18):1343-50.

4. Knowler WC, Barrett-Connor E, Fowler SE, Hamman RF, Lachin JM, Walker EA, et al: Reduction in the incidence of type 2 diabetes with lifestyle intervention or metformin. N Engl J Med 2002, 346(6):393-403.

5. Lindstrom J, Ilanne-Parikka P, Peltonen M, Aunola S, Eriksson JG, Hemio K, et al: Sustained reduction in the incidence of type 2 diabetes by lifestyle intervention: follow-up of the Finnish Diabetes Prevention Study. Lancet 2006, 368(9548):1673-9.

6. Knowler WC, Fowler SE, Hamman RF, Christophi CA, Hoffman HJ, Brenneman AT, et al: 10-year follow-up of diabetes incidence and weight 
loss in the Diabetes Prevention Program Outcomes Study. Lancet 2009, 374(9702):1677-86

7. Orozco L, Buchleitner AM, Gimenez-Perez G, Roqué i Figuls M, Richter B, Mauricio D: Exercise or exercise and diet for preventing type 2 diabetes mellitus. Cochrane Database of Systematic Reviews 2008, 3, Art. No.: CD003054.

8. Nield L, Summerbell CD, Hooper L, Whittaker V, Moore H: Dietary advice for the prevention of type 2 diabetes mellitus in adults. Cochrane Database of Systematic Reviews 2008, 3, Art. No.: CD005102.

9. Hamman RF, Wing RR, Edelstein SL, Lachin JM, Bray GA, Delahanty L, et al: Effect of weight loss with lifestyle intervention on risk of diabetes. Diabetes Care 2006, 29(9):2102-7.

10. Dansinger ML, Tatsioni A, Wong JB, Chung M, Balk EM: Meta-analysis: the effect of dietary counseling for weight loss. Ann Intern Med 2007, 147(1):41-50.

11. Curioni CC, Lourenco PM: Long-term weight loss after diet and exercise: a systematic review. Int J Obes (Lond) 2005, 29(10):1168-74.

12. Ash S, Reeves M, Bauer J, Dover T, Vivanti A, Leong C, et al: A randomised control trial comparing lifestyle groups, individual counselling and written information in the management of weight and health outcomes over 12 months. Int J Obes (Lond) 2006, 30(10):1557-64.

13. Berg TJ: Can type 2 diabetes be prevented? Tidsskr Nor Laegeforen 2000, 120(20):2430-3.

14. Lindstrom J, Tuomilehto J: The diabetes risk score: a practical tool to predict type 2 diabetes risk. Diabetes Care 2003, 26(3):725-31.

15. Schwarz PE, Li J, Lindstrom J, Tuomilehto J: Tools for predicting the risk of type 2 diabetes in daily practice. Horm Metab Res 2009, 41(2):86-97.

16. Silventoinen K, Pankow J, Lindstrom J, Jousilahti P, Hu G, Tuomilehto J: The validity of the Finnish Diabetes Risk Score for the prediction of the incidence of coronary heart disease and stroke, and total mortality. Eur $\int$ Cardiovasc Prev Rehabil 2005, 12(5):451-8.

17. Rubak S, Sandbaek A, Lauritzen T, Christensen B: Motivational interviewing: a systematic review and meta-analysis. Br I Gen Pract 2005, 55(513):305-12.

18. Pickering TG, Hall JE, Appel LJ, Falkner BE, Graves J, Hill MN, et al: Recommendations for blood pressure measurement in humans and experimental animals: Part 1: blood pressure measurement in humans: a statement for professionals from the Subcommittee of Professional and Public Education of the American Heart Association Council on High Blood Pressure Research. Hypertension 2005, 45(1):142-61.

19. Svilaas A, Strom EC, Svilaas T, Borgejordet A, Thoresen M, Ose L: Reproducibility and validity of a short food questionnaire for the assessment of dietary habits. Nutr Metab Cardiovasc Dis 2002, 12(2):60-70.

20. Foster C, Jackson AS, Pollock ML, Taylor MM, Hare J, Sennett SM, et al: Generalized equations for predicting functional capacity from treadmill performance. Am Heart J 1984, 107(6):1229-34.

21. The Physical Fitness Specialist Certification Manual, The Cooper Institute for Aerobics Research, revised 1997 printed in Advance Fitness Assessment \& Exercise Prescription. Edited by: Vivian H. Heyward; , 3 1998:48.

22. Myers J, Prakash M, Froelicher V, Do D, Partington S, Atwood JE: Exercise capacity and mortality among men referred for exercise testing. N Engl J Med 2002, 346(11):793-801.

23. Ross R, Bradshaw AJ: The future of obesity reduction: beyond weight loss. Nat Rev Endocrinol 2009, 5(6):319-25.

24. Han TS, Richmond P, Avenell A, Lean ME: Waist circumference reduction and cardiovascular benefits during weight loss in women. Int J Obes Relat Metab Disord 1997, 21(2):127-34.

25. Wang C, Harris WS, Chung M, Lichtenstein AH, Balk EM, Kupelnick B, et al: n-3 Fatty acids from fish or fish-oil supplements, but not alpha-linolenic acid, benefit cardiovascular disease outcomes in primary- and secondary-prevention studies: a systematic review. Am J Clin Nutr 2006, 84(1):5-17.

26. Mancia G, De BG, Dominiczak A, Cifkova R, Fagard R, Germano G, et al: 2007 Guidelines for the management of arterial hypertension: The Task Force for the Management of Arterial Hypertension of the European Society of Hypertension (ESH) and of the European Society of Cardiology (ESC). Eur Heart J 2007, 28(12):1462-536.

27. Johansson G, Wikman A, Ahren AM, Hallmans G, Johansson I: Underreporting of energy intake in repeated 24-hour recalls related to gender, age, weight status, day of interview, educational level, reported food intake, smoking habits and area of living. Public Health Nutr 2001, 4(4):919-27.

28. Lissner L: Measuring food intake in studies of obesity. Public Health Nutr 2002, 5(6A):889-92

29. Elobeid MA, Padilla MA, McVie T, Thomas O, Brock DW, Musser B, et al: Missing data in randomized clinical trials for weight loss: scope of the problem, state of the field, and performance of statistical methods. PLoS One 2009, 4(8):e6624.

30. Inelmen EM, Toffanello ED, Enzi G, Gasparini G, Miotto F, Sergi G, et al: Predictors of drop-out in overweight and obese outpatients. Int J Obes (Lond) 2005, 29(1):122-8.

31. Melin I, Reynisdottir S, Berglund L, Zamfir M, Karlstrom B: Conservative treatment of obesity in an academic obesity unit. Long-term outcome and drop-out. Eat Weight Disord 2006, 11(1):22-30.

32. Drewnowski A: Obesity, diets, and social inequalities. Nutr Rev 2009, 67(Suppl 1):S36-S39.

33. Darmon N, Drewnowski A: Does social class predict diet quality? Am J Clin Nutr 2008, 87(5):1107-17.

34. Svetkey LP, Stevens VJ, Brantley PJ, Appel LJ, Hollis JF, Loria CM, et al: Comparison of strategies for sustaining weight loss: the weight loss maintenance randomized controlled trial. JAMA 2008, 299(10):1139-48,

35. Chaston TB, Dixon JB: Factors associated with percent change in visceral versus subcutaneous abdominal fat during weight loss: findings from a systematic review. Int J Obes (Lond) 2008, 32(4):619-28.

36. Norris SL, Zhang X, Avenell A, Gregg E, Schmid CH, Lau J: Long-term nonpharmacological weight loss interventions for adults with prediabetes. Cochrane Database of Systematic Reviews 2005, 2, Art. No.: CD005270.

37. Droyvold WB, Nilsen TI, Kruger O, Holmen TL, Krokstad S, Midthjell K, et al: Change in height, weight and body mass index: Longitudinal data from the HUNT Study in Norway. Int J Obes (Lond) 2006, 30(6):935-9.

38. Flegal KM, Carroll MD, Ogden CL, Curtin LR: Prevalence and Trends in Obesity Among US Adults, 1999-2008. JAMA 2010, 4(7):382-93.

39. Crandall JP, Knowler WC, Kahn SE, Marrero D, Florez JC, Bray GA, et al: The prevention of type 2 diabetes. Nat Clin Pract Endocrinol Metab 2008, 4(7):382-93.

40. Berghofer A, Pischon T, Reinhold T, Apovian CM, Sharma AM, Willich SN: Obesity prevalence from a European perspective: a systematic review. BMC Public Health 2008, 8:200.

41. Wareham NJ, van Sluijs EM, Ekelund U: Physical activity and obesity prevention: a review of the current evidence. Proc Nutr Soc 2005, 64(2):229-47.

42. Lemmens VE, Oenema A, Klepp KI, Henriksen HB, Brug J: A systematic review of the evidence regarding efficacy of obesity prevention interventions among adults. Obes Rev 2008, 9(5):446-55.

43. Blackburn GL, Walker WA: Science-based solutions to obesity: what are the roles of academia, government, industry, and health care? Am J Clin Nutr 2005, 82(1 Suppl):207S-10S.

\section{Pre-publication history}

The pre-publication history for this paper can be accessed here: http://www.biomedcentral.com/1471-2458/11/893/prepub

doi:10.1186/1471-2458-11-893

Cite this article as: Nilsen et al.: Effects of lifestyle intervention in persons at risk for type 2 diabetes mellitus - results from a randomised, controlled trial. BMC Public Health 2011 11:893. 